\title{
Juglon (5-hydroxy-1,4-naphthalenedione) ve Ceviz Yaprağı Ekstraktının Turp (Raphanus sativus L.)’ta Bazı Gelişme Özellikleri ve Verim Üzerine Etkisi
}

\author{
Haluk Çağlar Kaymak \\ Atatürk Üniversitesi Ziraat Fakültesi Bahçe Bitkileri Bölümü, 25240-ERZURUM \\ (hckaymak@atauni.edu.tr)
}

Geliş Tarihi :28.11.2017

Kabul Tarihi :03.01.2018

\begin{abstract}
ÖZET: Bu araştırma, juglon (5-hydroxy-1,4-naphthalenedione) ve ceviz yaprağı ekstraktının turp (Raphanus sativus L.)'ta bazı gelişme özellikleri ve verim üzerine etkisini belirlemek amacı ile 2008-2009 yıllarında yürütülmüştür. Araştırmada, iki turp çeşidi (Raphanus sativus L. cvs. 'Beyaz ve Siyah'), juglon (5-hydroxy-1,4-naphthalenedione) ve ceviz yaprağı ekstraktı denenmiştir. Araşıırmada, yaprak sayısı (adet/bitki), kök çapı ve boyu (cm), ortalama kök ağırlığı (g), kökte kuru madde miktarı (\%) ve verim (kg/parsel) tespit edilmiștir. Juglon ve ceviz yaprağı ekstraktının turpta, incelenen parametrelerin tamamını olumsuz etkilediği tespit edilmiştir. Ayrıca, kökte kuru madde miktarı ve yaprak sayısı hariç, diğer parametrelerde Beyaz çeşidi Siyah çeşidine göre juglon ve ceviz yaprağı ekstraktından daha az etkilenmiştir. Araştırmada, en yüksek değerler her iki çeşitte de kontrol uygulamalarında elde edilirken, en düşük yaprak sayısı değeri Beyaz çeșidinde 2009 yllında juglon $(9.0$ adet/bitki) uygulamasında, en düşük kök çapı ve kök boyu sırasıyla 6.6 ve $5.9 \mathrm{~cm}$ olarak ceviz yaprağı eksraktında 2009 yılında, en düşük ortalama kök ağırlı̆̆ $(193.7 \mathrm{~g})$ ve verim $(4.6 \mathrm{~kg} /$ parsel) 2008 yılında Siyah çeşidinde juglon uygulamasında tespit edilmiştir. Araştırma sonuçlarına göre, hem juglon (5-hydroxy-1,4-naphthalenedione) hem de ceviz yaprağı ekstraktının turpta gelişme özellikleri ve verim üzerine olumsuz etkiye sahip olduğu söylenebilir.
\end{abstract}

Anahtar kelimeler: ceviz yaprăğ ekstraktı, juglon, turp, verim

\section{The Effect of Juglone (5-hydroxy-1,4-naphthalenedione) and Walnut Leaf Extract on Growth and Yield of Radish (Raphanus sativus L.)}

\begin{abstract}
The objective of this research was to determine the effect of juglon (5-hydroxy-1,4-naphthalenedione) and walnut leaf extract on growth and yield of radish (Raphanus sativus L.) during 2008-2009. In this study, two radish cultivar (Raphanus sativus L. cvs. 'Beyaz and Siyah') were used as plant material and juglone (5-hydroxy-1,4-naphthalenedione) and leaf walnut extract were tested. Leaf number, root length, diameter and weight, dry matter content of roots and yield were investigated. It was determined that walnut leaf extract and juglone affected negatively all examined parameters in radish. Moreover, cv. Beyaz was less impressed than cv. Siyah from juglone and walnut leaf extract in other parameters except for dry matter content of root and the leaf number. While the highest values were determined in cvs. Beyaz and Siyah in control in both experiment years, the lowest leaf number in cv. Beyaz in juglone in 2009, the lowest root length $(6.6 \mathrm{~cm})$ and diameter $(5.9 \mathrm{~cm})$ in walnut leaf extract in 2009 , the lowest root weight $(193.7 \mathrm{~g})$ and yield $(4.6 \mathrm{~kg} / \mathrm{plot})$ were determined in cv. Siyah in juglone in 2008. According to the results of this research, it can be said that both juglone (5-hydroxy-1,4-naphthalenedione) and walnut leaf extract have negative effect on yield and growth of radish.
\end{abstract}

Keywords: walnut leaf extract, juglone, radish, yield

\section{GíRiș}

Türkiye'de yaklaşı 23 milyon hektar toplam tarımsal alan içerisinde sebze üretim alanının payı yaklaş1k \%3 olup, 2016 verilerine göre 8.041.419 ha alanda sebze üretimi yapılmaktadır. Ülkemizde toplam 92 milyon ton kadar olan bitkisel üretimin \%29'unu, açıkta ve örtüaltında olmak üzere 27 milyon ton üretim miktarı ile sebze üretimi oluşturmaktadır. Ülkemizde yaygın üretilen sebzelerden birisi de turptur. Türkiye'de 200.000 ton kadar turp üretilmektedir. Turp üretiminin \%3'ünü beyaz turp, \%7'sini bayır (Siyah) turpu ve \%90'ını kırmızı turp oluşturmaktadır (TUIK, 2017). Turplar, diğer ülkelerde olduğu gibi Türkiye'de de geniş alanlarda yetiştirilmekte yazlık ve kışlık bir sebze olarak bütün yıl boyunca tüketilmektedir (Vural vd., 2000).

Türkiye'de açıkta sebze üretiminde ara tarımı da sıkça uygulanan bir üretim yöntemidir. Bu amaçla meyve bahçeleri tesis edilirken, fidanlar oluşturacakları taç genişliğinden $(10-15 \mathrm{~m})$ daha fazla aralıkla, örneğin 20-30 m aralıkla dikilerek, taç genişliğinden arta kalan boşlukta sebze yetiştiriciliği yapılır (Günay, 2005). Ancak bu üretim yönteminde, bir bitki tarafindan sentezlenen bazı kimyasal maddelerin başka bir bitkiyi olumlu veya olumsuz yönde etkilemesi olarak tarif edilen allelopatik etki (Kocaçalışkan, 2001) göz ardı edilmemelidir. Bu tip allelopatik etkiye sahip türler içerisinde ihlamur, akçaağaç, kayın, huş, akasya, kavak ve ceviz örnek gösterilebilir (Könnecke, 1965; Kitou, 1999; Khan vd., 2001; Kocaçalışkan ve Terzi, 2001). Allelopatik etkiye sahip bu türler içerisinde en dikkat çekici olanlardan biri de cevizdir. Ceviz, Türkiye'de 868.528 da üretim alanı, 8.171.185 adet meyve veren ağaç sayısı ve 195.000 ton üretim miktarı ile önemli meyve türlerinden bir tanesidir (TUIK, 2017). Cevizdeki allelopatik etki, normalde toksik olmayan, renksiz, yapraklarda, sürgünlerde, meyvenin yeşil 
kabuğunda ve köklerde sentezlenen hidrojuglon isimli allelokimyasalın; hava veya toprakla temas ettiğinde oksitlenerek zehirli bir formu olan juglon'a (5-hydroxy-1,4-naphthalenedione) dönüşmesiyle ortaya çıkmaktadır (Rietveld, 1983; Tekintaş vd., 1988; Jose ve Gillespie, 1998; Appleton vd., 2000). $\mathrm{Bu}$ allelokimyasalın yağmur suları ile yıkanıp toprağa karışarak birçok otsu ve odunsu bitki üzerinde zehir etkisi yaptığı bilinmektedir (Rietveld, 1983).

Özellikle Türkiye'nin doğusunda ağaç tabanlı karışık kültür yetiştiriciliğinde yüksek getirisi, estetik görüntüsü, verimi, hızlı büyüme potansiyeli ve bölgeye adaptasyon kabiliyetinin iyi olması gibi nedenlerle en yaygın kullanılan tür ceviz (Juglans regia L.)'dir (Thevathasan vd., 1999; Ercişli vd. 2005). Bu tip birlikte yetiştiricilikte ceviz ağaçları ile girilen rekabet sonucunda üretimi yapılan diğer türün veriminin önemli derecede düştüğü yapılan çalışmalar sonucunda ortaya konulmuştur (José vd., 1995). Örneğin Solanaceae familyası türlerinden domates, biber ve patlıcanın juglona karşı çok hassas olduğu, allelopatik etki sonucu önce yaprakların sarardığı ve ilerleyen süreçte bitkilerin öldüğü tespit edilmiştir (Rice, 1984). Bu nedenle, bölgede ceviz ağaçları ile birlikte yetiştirilebilecek türlerin belirlenmesi veya türlerin juglona karşı tepkilerinin ortaya konulması gerekmektedir. Elde edilen literatür bilgileri ş̧ı̆̆ı altında juglonun turp üzerine allelopatik etkisi hakkında bilgilerin sınırlı olduğu belirlenmiştir. $\mathrm{Bu}$ nedenle, bu araştırma, juglon (5-hydroxy-1,4naphthalenedione) ve ceviz yaprağ (Raphanus sativus L.)'ta bazı gelişme özellikleri ve verim üzerine etkisini belirlemek amacıyla yürütülmüştür.

\section{MATERYAL VE METOT}

$\mathrm{Bu}$ çalışma, Atatürk Üniversitesi, Ziraat Fakültesi, Bahçe Bitkileri Bölümü'nde 2008 ve 2009 yıllarında iki yıl süre ile yürütülmüştür. Araştırmada, bitkisel materyal olarak iki turp çeşidi (Raphanus sativus L. cvs. 'Beyaz ve Siyah') kullanılırken, juglon (5-hydroxy-1,4-naphthalenedione) ve ceviz yaprağı ekstraktının verim ve gelişme özellikleri üzerine etkileri incelenmiştir.

Araştırmada, tohum ekimi hazırlanan tavalara sira arası ve sira üzeri mesafeler $40 \times 20 \mathrm{~cm}$ olacak şekilde her iki deneme yılında da Temmuz ayının ilk haftasında yapılmıştır. Bitkiler 3-4 yapraklı döneme geldiğinde seyreltme elle yapılmıştır. Gübrelemede,

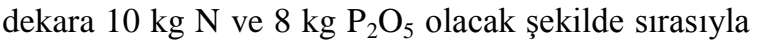
kalsiyum amonyum nitrat ve triple süper fosfat gübreleri kullanılmıştır. Kullanılan $\mathrm{P}_{2} \mathrm{O}_{5}$ 'in tamamı ve N'in yarısı ekimle birlikte, N'in diğer yarısı çıkıştan 20 gün sonra toprak yüzeyine elle serpilerek, toprağa karıştırılmıştır. Sulama, ihtiyaca göre yüzey sulaması şeklinde gerçekleştirilmiştir. Diğer kültürel işlemler parseller arasında fark oluşturmayacak şekilde homojen olarak yapılmıştır (Kaymak ve Güvenç, 2007).

Araştırmada, yaprak ekstraktı hazırlamak için kullanılacak yapraklar 7 yaşından büyük ceviz ağaçlarından toplanmıştır. Nitekim, ceviz ağaçları 7 yaşına kadar yapraklarında toksik etki yapacak düzeyde juglon üretmemektedirler ve juglon seviyesi Temmuz ayının son haftası ile Ağustos ayının ilk haftası arasındaki dönemde en yüksek seviyeye ulaşmaktadır (Piedrahita, 1984; Tekintaş vd., 1988; Kocaçalışkan ve Terzi, 2001). Bu nedenle, araştırmada kullanılan ceviz yaprakları (Juglans regia cv. 'Şebin') Temmuz ayının son haftasında belirtilen özellikteki ceviz bahçesinden toplanmıştır. Toplanan bu yapraklar, etüvde $68^{\circ} \mathrm{C}$ 'de 48 saat kurutulmuştur. Daha sonra ekstrakt hazırlamak için, $10 \mathrm{~g}$ öğütülmüş ceviz yaprağ 1 için $100 \mathrm{ml}$ saf su olacak şekilde hazırlanan karışım karıştırıcı kullanılarak homojen hale getirilip süzülmüştür. Hazırlanan çözelti, 3000 rpm'de santrifüj edildikten sonra elde edilen süzük deneme parsellerinde kullanılmıştır (Kocaçalışkan ve Öğütçü, 1999; Kocaçalışkan ve Terzi, 2001).

Araştırmada kullanılan sentetik juglon çözeltisi ise $10^{-3} \mathrm{M}$ olarak hazırlanmıştır (Kocaçalışkan ve Terzi, 2001). Bu amaçla, juglon çözeltisi $0.174 \mathrm{~g}$ juglon (Sigma Chem. Co., Mo, USA) 1 litre saf su içerisine konulduktan sonra $40^{\circ} \mathrm{C}$ 'de 24 saat otomatik karıştırıcıda karıştırılarak hazırlanmıştır (Jose ve Gillespie, 1998).

Bütün parsellerde iki kenar sırasındaki bitkiler kenar tesiri olarak bırakılarak iç sırada kalan bitkilerde yaprak sayısı (adet/bitki), kök çapı ve boyu (cm), ortalama kök ağırlığı (g), kökte kuru madde miktarı (\%) ve verim (kg/parsel) tespit edilmiştir.

Araştırma, 3 farklı uygulama (kontrol, juglon $\left(10^{-3} \mathrm{M}\right)$, yaprak ekstraktı) ve 2 çeşit olmak üzere $3 \times 2$ Faktöriyel Düzende Tam Şansa Bağlı Deneme Planı'na göre 4 tekrarlı olarak yürütülmüştür. Varyans analizleri sonucu önemli bulunan uygulamalar arasındaki fark Duncan Çoklu Karşılaştırma Testi kullanılarak belirlenmiştir.

\section{BULGULAR ve TARTIŞMA}

Turp çeşitlerinde ceviz yaprağı ekstraktı ve juglonun yaprak sayısı üzerine etkisi Çizelge 1'de sunulmuştur. Hem çeşitlerin hem de uygulamaların ortalamaları arasındaki farkın istatistiksel anlamda önemli olduğu $\quad(P<0.05) \quad$ belirlenmiştir. Uygulamaların etkisi çeşitlere göre değişmekle birlikte, genel ortalamalar dikkate alındığında en düşük yaprak sayısı juglon uygulamasında (10.4 adet/bitki) en yüksek yaprak sayısı ise kontrolde (12.5 adet/ bitki) tespit edilmiştir. Bununla birlikte, en yüksek yaprak sayısı (13.5 adet/bitki) Siyah 
Çizelge 1. Ceviz yaprağı ekstraktı ve juglonun turpta yaprak sayısına etkisi (adet/bitki)

\begin{tabular}{|c|c|c|c|c|c|}
\hline Çeșit & Muamele & 2008 & 2009 & Yil Ortalama & \\
\hline \multirow{3}{*}{ Beyaz } & Kontrol & $11.5^{\mathrm{NS}}$ & $11.5^{\mathrm{NS}}$ & 11.5 & \multirow{3}{*}{$10.5 \mathrm{~B} *$} \\
\hline & Ekstrakt & 10.5 & 11.0 & 10.8 & \\
\hline & Juglon & 9.5 & 9.0 & 9.3 & \\
\hline \multirow{3}{*}{ Siyah } & Kontrol & $13.5 \mathrm{a}^{*}$ & $13.5^{\mathrm{NS}}$ & 13.5 & \multirow{3}{*}{$12.6 \mathrm{~A}$} \\
\hline & Ekstrakt & $13.0 \mathrm{ab}$ & 12.5 & 12.8 & \\
\hline & Juglon & $11.5 \mathrm{~b}$ & 11.5 & 11.5 & \\
\hline \multirow{3}{*}{ Ortalama } & Kontrol & 12.5 & 12.5 & $12.5 \mathrm{~A}^{*}$ & \\
\hline & Ekstrakt & 11.8 & 11.8 & $11.8 \mathrm{AB}$ & \\
\hline & Juglon & 10.5 & 10.3 & 10.4 B & \\
\hline
\end{tabular}

$(*) \% 5$ ihtimal seviyesinde önemli, (NS) \% 5 ihtimal seviyesinde önemsiz

çeşidinde kontrolde 2008 ve 2009 ylllarında, en düşük yaprak sayısı ise Beyaz çeşidinde ( 9.0 adet/bitki) juglon uygulamasinda 2009 yılinda saptanmıştır.

Çizelge 2 incelendiğinde turp çeşitlerinde ceviz yaprağı ekstraktı ve juglonun kök çapı, boyu ve ağırlı̆̆ına etkisi görülecektir. En düşük kök çapı ve kök boyu sirasiyla 6.6 ve $5.9 \mathrm{~cm}$ (Siyah) olarak ceviz yaprağı eksraktında 2009 yılında, en düşük ortalama kök ağırlığı 193.7 g ile 2008 yılında Siyah çeşidinde Juglon uygulamasında tespit edilirken, en yüksek kök çapı ve kök boyu ve ortalama kök ağırlığı değerleri her iki deneme yılında da çeşitlerin tamamında kontrolde tespit edilmiştir. Bununla birlikte, genel ortalamalar dikkate alındığında da hem çeşitlerin hem de uygulamaların ortalamaları arasındaki farkın istatistiksel anlamda önemli olduğu $(P<0.05)$ belirlenmiştir.

Çizelge 2. Ceviz yaprağı ekstraktı ve juglonun turpta kök çapı $(\mathrm{cm})$, boyu (cm) ve ağırlı̆̆ına (g) etkisi

\begin{tabular}{|c|c|c|c|c|c|}
\hline \multirow[b]{2}{*}{ Çeșit } & \multirow[b]{2}{*}{ Muamele } & 2008 & 2009 & Yil Ortalama & \\
\hline & & \multicolumn{4}{|c|}{ Kök Çapı (cm) } \\
\hline \multirow{3}{*}{ Beyaz } & Kontrol & $9.7 \mathrm{a}^{*}$ & $8.8 \mathrm{a}^{*}$ & 9.3 & \multirow{3}{*}{$8.8 \mathrm{~A}^{*}$} \\
\hline & Ekstrakt & $9.0 \mathrm{ab}$ & $8.1 \mathrm{~b}$ & 8.5 & \\
\hline & Juglon & $8.7 \mathrm{~b}$ & $8.6 \mathrm{ab}$ & 8.6 & \\
\hline \multirow{3}{*}{ Siyah } & Kontrol & $8.4 \mathrm{a}^{*}$ & $8.0 \mathrm{a}^{*}$ & 8.2 & \multirow{3}{*}{$7.3 \mathrm{~B}$} \\
\hline & Ekstrakt & $6.9 \mathrm{~b}$ & $6.6 \mathrm{~b}$ & 6.7 & \\
\hline & Juglon & $7.3 \mathrm{~b}$ & $6.8 \mathrm{~b}$ & 7.0 & \\
\hline Çeşit & Kontrol & 9.0 & 8.4 & $8.7 \mathrm{~A}^{*}$ & \\
\hline \multirow[t]{3}{*}{ Ortalama } & Ekstrakt & 7.9 & 7.3 & $7.6 \mathrm{~B}$ & \\
\hline & Juglon & 8.0 & 7.7 & $7.8 \mathrm{~B}$ & \\
\hline & & \multicolumn{3}{|c|}{ Kök Boyu (cm) } & \\
\hline \multirow{3}{*}{ Beyaz } & Kontrol & $9.4 a^{*}$ & $7.9 \mathrm{a}^{*}$ & 8.6 & \multirow{3}{*}{$7.7 \mathrm{~A}^{*}$} \\
\hline & Ekstrakt & $7.3 \mathrm{~b}$ & $6.9 \mathrm{~b}$ & 7.1 & \\
\hline & Juglon & $7.6 \mathrm{~b}$ & $7.2 \mathrm{~b}$ & 7.4 & \\
\hline \multirow{3}{*}{ Siyah } & Kontrol & $7.9 \mathrm{a}^{*}$ & $7.6 \mathrm{a}^{*}$ & 7.7 & \multirow{3}{*}{$6.7 \mathrm{~B}$} \\
\hline & Ekstrakt & $6.0 \mathrm{~b}$ & $5.9 \mathrm{~b}$ & 5.9 & \\
\hline & Juglon & $6.4 \mathrm{ab}$ & $6.5 \mathrm{ab}$ & 6.4 & \\
\hline Çeşit & Kontrol & 8.6 & 7.7 & $8.2 \mathrm{~A}^{*}$ & \\
\hline \multirow[t]{2}{*}{ Ortalama } & Ekstrakt & 6.6 & 6.4 & $6.5 \mathrm{~B}$ & \\
\hline & Juglon & 7.0 & 6.8 & $6.9 \mathrm{~B}$ & \\
\hline & & \multicolumn{2}{|c|}{ Ortalama Kök Ağırlığı (g) } & & \\
\hline \multirow{3}{*}{ Beyaz } & Kontrol & $524.3 \mathrm{a}^{*}$ & $395.7 \mathrm{a}^{*}$ & 460.0 & \multirow{3}{*}{$386.1 \mathrm{~A}^{*}$} \\
\hline & Ekstrakt & $365.4 \mathrm{~b}$ & $310.6 \mathrm{~b}$ & 338.0 & \\
\hline & Juglon & $371.4 \mathrm{~b}$ & $349.3 \mathrm{~b}$ & 360.3 & \\
\hline \multirow{3}{*}{ Siyah } & Kontrol & $320.5 \mathrm{a}^{*}$ & $307.9 \mathrm{a}^{*}$ & 314.2 & \multirow[b]{3}{*}{$245.7 \mathrm{~B}$} \\
\hline & Ekstrakt & $228.0 \mathrm{~b}$ & $206.9 \mathrm{~b}$ & 217.4 & \\
\hline & Juglon & $193.7 \mathrm{~b}$ & $217.4 \mathrm{~b}$ & 205.5 & \\
\hline Çeşit & Kontrol & 422.4 & 351.8 & $387.1 \mathrm{~A}^{*}$ & \\
\hline \multirow[t]{2}{*}{ Ortalama } & Ekstrakt & 296.7 & 258.7 & $277.7 \mathrm{~B}$ & \\
\hline & Juglon & 282.5 & 283.3 & $282.9 \mathrm{~B}$ & \\
\hline
\end{tabular}

(*) \% 5 ihtimal seviyesinde önemli 
Juglon (5-hydroxy-1,4-naphthalenedione) ve Ceviz Yaprağı Ekstraktının Turp (Raphanus sativus L.)’ta Bazı Gelişme Özellikleri ve Verim Üzerine Etkisi

Turp çeşitlerinde ceviz yaprağı ekstraktı ve juglonun kökteki kuru madde miktarına etkisi Çizelge 3'te görülmektedir. Kuru madde miktarı, her iki çeşitte de hem ceviz yaprağı ekstraktı hem de juglon uygulamasında kontrole göre azalmıştır. Bunun yanında, en düşük kuru madde miktarı Beyaz çeşidinde juglon uygulamasında (\%4.1), en yüksek kuru madde miktarı Siyah çeşidinde kontrolde (\%9.2) 2008 yılında tespit edilmiştir. Ayrıca, genel ortalamalar dikkate alındığında ise kuru madde miktarı \%6.1 (ceviz yaprağı ekstraktı) ile \%6.9 (kontrol) arasında değişmiştir.

Çizelge 3. Ceviz yaprağı ekstraktı ve juglonun turpta kökteki kuru madde miktarına (\%) etkisi

\begin{tabular}{|c|c|c|c|c|c|}
\hline Çeşit & Muamele & 2008 & 2009 & Yıl Ortalama & \\
\hline \multirow{3}{*}{ Beyaz } & Kontrol & $5.0 \mathrm{a}^{*}$ & $4.8 \mathrm{a}^{*}$ & 4.9 & \multirow{3}{*}{$4.5 \mathrm{~B} *$} \\
\hline & Ekstrakt & $4.2 \mathrm{~b}$ & $4.8 \mathrm{a}$ & 4.5 & \\
\hline & Juglon & $4.1 \mathrm{~b}$ & $4.4 \mathrm{~b}$ & 4.3 & \\
\hline \multirow{3}{*}{ Siyah } & Kontrol & $9.2 \mathrm{a}^{*}$ & $8.5 \mathrm{a}^{*}$ & 8.9 & \multirow{3}{*}{$8.3 \mathrm{~A}$} \\
\hline & Ekstrakt & $8.9 \mathrm{ab}$ & $6.7 \mathrm{~b}$ & 7.8 & \\
\hline & Juglon & $7.8 \mathrm{~b}$ & $8.5 \mathrm{a}$ & 8.2 & \\
\hline \multirow{3}{*}{ Ortalama } & Kontrol & 7.1 & 6.6 & $6.9 \mathrm{~A}^{*}$ & \\
\hline & Ekstrakt & 6.5 & 5.7 & $6.1 \mathrm{~B}$ & \\
\hline & Juglon & 6.0 & 6.4 & $6.2 \mathrm{~B}$ & \\
\hline
\end{tabular}

(*) \% 5 ihtimal seviyesinde önemli

Turp çeşitlerinde ceviz yaprağı ekstraktı ve juglonun verim üzerine etkisi Çizelge 4'te sunulmuştur. Hem çeşitlerin hem de uygulamaların ortalamaları arasındaki farkın istatistiksel anlamda önemli olduğu $(P<0.05)$ tespit edilirken, her iki uygulamanın da hem genel ortalamalar dikkate alındığında hem de her iki deneme yılında da verim üzerine olumsuz etki yaptı̆̆ her iki deneme yılında da, en yüksek verim değerleri Beyaz çeşidinde sirasıyla $12.6 \mathrm{~kg} / \mathrm{parsel}$ ve 9.5 $\mathrm{kg} /$ parsel olarak kontrolde tespit edilmiştir. En düşük verim ise Siyah çeşidinde $4.6 \mathrm{~kg} /$ parsel olarak 2008 yılında juglon uygulamasında belirlenmiştir.

Çizelge 4. Ceviz yaprağı ekstraktı ve juglonun turpta verime (kg/parsel) etkisi

\begin{tabular}{|c|c|c|c|c|c|}
\hline Çeşit & Muamele & 2008 & 2009 & Yll Ortalama & \\
\hline \multirow{3}{*}{ Beyaz } & Kontrol & $12.6 \mathrm{a}^{*}$ & $9.5 \mathrm{a}^{*}$ & 11.0 & \multirow{3}{*}{$9.3 \mathrm{~A}^{*}$} \\
\hline & Ekstrakt & $8.8 \mathrm{~b}$ & $7.5 \mathrm{~b}$ & 8.1 & \\
\hline & Juglon & $8.9 \mathrm{~b}$ & $8.4 \mathrm{ab}$ & 8.6 & \\
\hline \multirow{3}{*}{ Siyah } & Kontrol & $7.7 a^{*}$ & $7.4 \mathrm{a}^{*}$ & 7.5 & \multirow{3}{*}{$5.9 \mathrm{~B}$} \\
\hline & Ekstrakt & $5.5 \mathrm{ab}$ & $5.0 \mathrm{~b}$ & 5.2 & \\
\hline & Juglon & $4.6 \mathrm{~b}$ & $5.2 \mathrm{~b}$ & 4.9 & \\
\hline \multirow{3}{*}{ Ortalama } & Kontrol & 10.1 & 8.4 & $9.3 \mathrm{~A}^{*}$ & \\
\hline & Ekstrakt & 7.1 & 6.2 & $6.7 \mathrm{~B}$ & \\
\hline & Juglon & 6.8 & 6.8 & $6.8 \mathrm{~B}$ & \\
\hline
\end{tabular}

(*) \% 5 ihtimal seviyesinde önemli

Araştırmada kullanılan turp çeşitlerinde, yaprak sayısı, kök ağırlığı ve ebadı, kökte kuru madde miktarı ve verim çeşitlere göre değişmekle birlikte, ceviz yaprağı ekstraktı ve juglon uygulamasından da olumsuz etkilendiği belirlenmiştir. İncelenen parametrelerin tamamında en yüksek değerler her iki deneme yılında da kontrolde elde edilirken en düşük değerler juglon uygulamasında elde edilmiştir. Araştırma sonuçları incelendiğinde juglon uygulamasının olumsuz etkisinin ceviz yaprağ1 ekstraktına göre daha fazla olduğu söylenebilir. Ayrıca, kökte kuru madde miktarı ve yaprak sayısı hariç, diğer parametrelerde Beyaz çeşidi Siyah çeşidine göre juglon ve ceviz yaprağı ekstraktından daha az etkilenmiştir. Nitekim, daha önce yapılan araştırmalarda da juglonun elma, üzüm, patates ve domates gibi birçok faklı türde bitki büyüme gelişmesi üzerine olumsuz etki yaptığı tespit edilmiştir (Rietveld, 1983; Coder, 1999; Appleton vd., 2000). Ayrıca, bu araştırmalarda juglonun bitki büyüme ve gelişmesini hem fotosentez ve respirasyonu azaltarak hem de oksidatif stresi artırarak inhibe ettiği belirlenmiştir (Hejl vd., 1993; Jose ve Gillespie, 1998; Segura-Aguilar vd., 1992). 
Juglon nedeniyle stomalarda meydana bozulma sonucunda fotosentezin dolaylı olarak etkilendiği ve sonuçta ister dolaylı ister direkt olarak fotosentezin juglon tarafindan inhibe edilmesi sonucu bitki büyümesinin azaldığı bildirilmiştir (Ercişli ve Turkkal, 2005). Bununla birlikte, Kocaçalışkan ve Terzi (2001) juglonun ve ceviz yaprağı ekstraktının karpuz, domates ve tere gibi sebze türlerinde çimlenmeyi ve fide gelişimini olumsuz etkilediğini tespit etmiştir. Benzer şekilde, Ercişli vd. (2005) çilekte yaprak sayısı, yaprak alanı, bitki başına ortalama meyve sayısı ve ağırlığı, taze kök ağırlığı, vitamin C miktarı, titre edilebilir asitlik ve verimin juglon ve yaprak ekstraktı uygulamalarında kontrole göre azaldığını ve bitki besin elementlerinin alımını engellediğini belirlemişlerdir. Ayrıca, juglonun hem katyon alım kapasitesini düşürdügünü hem de yaprak analizleri sonucu bitki besin elementlerinin juglon ve yaprak ekstraktı uygulamalarında kontrole göre düşük olduğunu tespit etmişlerdir.

Araştırma sonuçlarına göre juglon ve ceviz yaprağı ektsraktı uygulamalarının turpta incelenen parametrelerin tamamında olumsuz etki yaptığ 1 tespit edilmiştir. Ara tarımı şeklinde yapılan sebze üretiminde, sadece cevizin değil, bu tip olumsuz allelopatik etkiye sahip türlerin tamamı başarılı bir sebze üretimi için dikkate alınmalıdır.

\section{KAYNAKLAR}

Appleton B., Berrier R., Haris R., Alleman B., Swanson L., 2000. Trees for problem landscape sites-the walnut tree: Allelopathic effects and tolerant plants. Virginia State University, Virginia Cooperative Extension. Publication No. 430-021.

Coder, K.D., 1999. Allelopathy in trees. Arborist News, 8: 53-60.

Ercisli, S., Esitken A., Turkkal C., Orhan E., 2005. The allelopathic effects of juglone and walnut leaf extracts on yield, growth, chemical and PNE compositions of strawberry cv. Fern. Plant Soil Environ., 51(6): 283-287.

Ercisli, S., Türkkal, C. 2005. Allelopathic effects of juglone and walnut leaf extracts on growth, fruit yield and plant tissue composition in strawberry cvs. 'Camarosa' and 'Sweet Charlie', The Journal of Horticultural Science and Biotechnology, 80:1, 39-42.

Günay, A., 2005. Sebze Yetiştiriciliği, Cilt:II. S:531, İzmir.

Hejl, A.M., Einhellig F.A., Rasmussen, J., 1993. Effects of juglone on growth, photosynthesis and respiration. Journal of Chemical Ecology, 19: 559-568.
Jose, S., Gillespie, A.R., 1998. Allelopathy in black walnut (Juglans nigra L.) alley cropping: II. Effects of juglone on hydroponically grown corn (Zea mays L.) and soybean (Glycine $\max$ L. Merr) growth and physiology. Plant and Soil, 203: 199-205.

José, S., Gillespie, A.R. Siefert, J.E., 1995. The microenvironmental and physiological basis for temporal reductions in crop production in an Indiana alley cropping system. In: Proceedings of the 4th North American Agroforestry Conference: Growing a Sustainable Future. (Ehrenreich, J. H., Ehrenreich, D. L. and Lee, H. W., Eds.), University of Idaho, Moscow, ID, USA, 54-6.

Kaymak, H.C., Güvenç İ., 2007. Farklı Ekim Zamanlarının Turp (Raphanus sativus L.)'ta Bazı Gelişme Özellikleri ve Verime Etkisi. Alınteri Bilim ve Kültür Dergisi, 12(B):6-12.

Khan, P.A., Mughal, A.H.İ., Khan, M.A., 2001. Allelopathic effects of leaf axtract of populus deltoides on germination and seedling growth of some vegetables. Range managment and Agroforestry vol. 22(2): 231-236.

Kitou, M., 1999, Changes in allelopathic potential in relation to incubation conditions of soil mixed with Acacia pubescens (Venten) leaf powder. Journal of Weed Science and Technology vol. 44(4): 309-315.

Kocaçalışkan, İ., Öğütçü, H., 1999. Bazı bitki tohumlarının çimlenmesi ve fide büyümesi üzerine yonca özütlerinib etkisi. DPÜ Fen Bil. Derg., 1:, 39-49.

Kocaçalışkan, İ., 2001, Allelopati. DPÜ Fen-Edebiyat Fakültesi Biyoloji Bölümü. Kütahya.

Kocaçalışkan, İ., Terzi, İ., 2001. Allelopathic effects of walnut leaf extracts and juglone on seed germination and seedling growth. Journal of Horticultural Science \& Biotechnology, 76(4): 436-440.

Könnecke, G., 1965. Fruchtfolgen Veb. Alman Tarım Yayınevi. (Türkiye Şeker Fabrikaları A.Ş. Yayınları: No: 207, Ankara.

Piedrahita, O., 1984. Black walnut toxicity. Ministry of Agriculture and Food, Ontario, Canada. Order No. 80-050.

Rietveld, W.J., 1983. Allelopathic effects of juglone on germination and growth of several herbaceous and woody species. Journal of Chemical Ecology, 9: 295-308.

Rice, E.L., 1984. Allelopathy. Academic Press, Orlando, FL., USA.

Segura-Aguilar J., Hakman I., Rydstrom J. 1992. The effect of 5$\mathrm{OH}-1,4$ naphtoquinone on Norway spruce seed during germination. Plant Physiology, 100: 1955-1961.

Tekintaş E., Tanrısever A., Mendilcioğlu K., 1988. Cevizlerde (Juglans regia L.) juglon izolasyonu ve juglon içeriğinin yıllık değişimi. Ege Üniversitesi Ziraat Fakültesi Dergisi, 25: 214-225.

Thevathasan N.V., Gordon A.M., Voroney R.P. 1999. Juglone (5hydroxy-1,4 napthhoquinone) and soil nitrogen transformation interaction under a walnut plantation in southern Ontario, Canada. Agroforestry Systems, 44: 151162.

TUIK. 2017. https://biruni.tuik.gov.tr/bitkiselapp/bitkisel.zul (27 Kasim 2017)

Vural, H., Eşiyok, D., Duman, İ., 2000. Kültür Sebzeleri (Sebze Yetiştirme). Ege Üniversitesi Ziraat Fakültesi Bahçe Bitkileri Bölümü, Bornova-İzmir, 440s. 